\title{
Castro Buendía, G (2014): Génesis musical del cante flamenco. De lo remoto a lo tangible en la música flamenca hasta la muerte de Silverio Franconetti. Sevilla: Libros con duende, 2 vols., 1.786 pp. ISBN: 978-8415718239
}

La presente publicación es fruto de la tesis doctoral del autor. Su exorbitante volumen indica que se trata de un trabajo complejo difícil de resumirlo y debatirlo adecuadamente en el espacio de una reseña.

La pregunta más pertinaz sería quizás la del porqué de esta empresa. Puede haber dos razones: Por un lado, parece evidente que la crecida complejidad del arte flamenco ha prosperado de una manera increíble a partir de los años 70 del siglo pasado, alcanzando un estatus universal que se refleja en su declaración como Patrimonio Cultural Inmaterial de la Humanidad por parte de la UNESCO en 2010. Por otro lado, las numerosas deficiencias de los escasos análisis musicológicos del género flamenco exigen respuestas más fiables. La obra de Castro intenta responder a esta dialéctica entre música y ciencia que provocó el giro radical tanto en la realidad del flamenco como en su explicación a base de las aportaciones de investigadores de otras disciplinas presentadas a lo largo de los últimos 25 años. Desde entonces el interés de de artistas e investigadores se centra en nuevas vías teórica- y metodológicamente más adecuadas para aclarar el origen y las características del cante, toque y baile flamenco. Los nuevos conocimientos animaron la renovación exitosa de este arte. La renovación conceptual no ocurrió exactamente en el marco de la musicología española que había ignorado el flamenco pensando que se trata de un género indecente, indigno para los templos de la música y la reflexión sobre ello. El salto cualitativo en este sentido ocurrió más bien en el marco de la etnomusicología debido a la intrusión de investigadores de las ciencias sociales y culturales. Estos entraron en un terreno fértil, explorando una creciente cantidad de datos que contrastaron con los diversos mitos basados en la sangre gitana y el alma del pueblo andaluz o refugiándose en una ominosa razón incorpórea. Una vez rechazado el mito, el paisaje artístico-musical del flamenco volvió ser un reto al que respondieron no sólo los académicos de diversas disciplinas sino también los artistas del flamenco, que durante los años 70 buscaban nuevas formas de expresión y de identidad a consecuencia de su auto-liberación del tradicionalismo asfixiante.

El descubrimiento de la dimensión social, cultural y poético-lingüística del flamenco puso de manifiesto la necesidad de profundizar en el análisis musicológico casi inexistente hasta este momento y reclamado ya por el romanista y lingüista austríaco y amigo del primer flamencólogo, Antonio Machado y Álvarez (Demófilo), Hugo Schuchardt. En su famosa réplica de 1881 a la Colección de cantes flamencos de su amigo sevillano confesó su ignorancia respecto al origen de la música flamenca y reclamó la necesidad de investigar su dimensión musical. Sus palabras quedaron en el aire hasta el comienzo de la segunda década del siglo XX, cuando compositores y musicólogos como Joaquín Turina y Manuel de Falla se acercaron al tema con unas sugerentes pero infundadas observaciones inútiles para la musicología misma. Fue más bien el folclorista y etnomusicólogo Manuel García Matos quien, en 1944 abrió las puertas a la investigación empírica del flamenco como elemento integral de la música tradicional y popular de la Península, su principal objeto de estudio hasta finales de la década de los años 1960. Poco después, en 1966, Hipólito Rossy presentó un extenso estudio monográfico sobre el cante jondo o flamenco. Habría que destacar que las publicaciones de ambos investigadores tuvieron lugar durante el periodo del imperante mairenismo, por lo que sus conclusiones contrastaron ampliamente $y$ "por naturaleza" con las tesis de Antonio Mairena y Ricardo Molina formuladas en su obra Mundo y formas del cante flamenco. Quizás por esta razón su influencia en el estudio del flamenco tardaría unos veinte años más en dar sus frutos.

El primer reflejo a los impulsos dados por la investigación musicológica en el terreno de la flamencología tuvo lugar en la década de los 1990, cuando el compositor sevillano José Romero Jiménez en vista del emergente giro en la investigación del flamenco - intentó en 1996 revisar las bases musicológicas del flamenco en sus dos tomos de La otra historia del flamenco basándose en la tradición semítico musical andaluza. No obstante, fracasó en última instancia porque creyó haber encontrado el origen del flamenco en el siglo IX, confundiendo el flamenco con la música andalusí de la época. Dos años más tarde, en 1998, los hermanos Antonio y David Hurtado intentaron lo mismo. A pesar de que aseguraron a los lectores en las primeras líneas de su libro El arte de la escritura musical flamenca que el flamenco "ahonda sus raíces en el pueblo llano", inmediatamente después confesaron que "nunca podremos llegar a saber dónde, cómo y cuándo surgió el Flamenco". No obstante, su aportación dedicada especialmente a la estética flamenca defendió que lo ancestral en el flamenco, lo supuestamente puro, lo jondo, es pura fantasía y no remonta más allá que algunas décadas (ibíd. 35). A diferencia de esta incertidumbre que separa el "material musical" del flamenco de su estética, la obra de Castro intenta explicar la estética flamenca como elemento diferencial de la evolución musical del flamenco en el marco de la música en general. 
Su obra se comprende como intento de superar las debilidades de los anteriores estudios musicológicos del género andaluz. Los supera por dos razones principales: Por un lado, el autor - en evidente concordancia con la sociología de la música de Kurt Blaukopf- ha entendido el flamenco como material sonoro organizado en el marco de una sociedad concreta y la cultura como fuente de sentido que guía la acción musical. Lo analiza como objeto naturalcultural siguiendo la metodología de las ciencias sociales y culturales, es decir, completa, contrasta y compara los datos procedentes de un análisis relacional, sistemático y rígido de la música en España a partir de los documentos y datos encontrados a lo largo de los últimos tres siglos. Por otro lado, la combinación de los resultados del análisis musicológico del emergente flamenco como estilo musical con los conocimientos de su desarrollo a partir del siglo XVII en el marco de la sociedad y cultura de España, presentados a lo largo de las últimas décadas, le permite corroborar los datos existentes y profundizar en el análisis en todas las direcciones.

A pesar de todo esto habría que destacar una insuficiencia metodológica significativa que probablemente es debido a la todavía llamativa falta de comunicación entre las disciplinas implicadas y de integración del análisis musical en el análisis social y cultural. Eso sobre todo porque la sociología de la música, la antropología y la filosofía pueden aportar mucho a la musicología siempre cuando esta no se encierra en su torre de marfil y considera al arte musical como algo ajeno a la vida cotidiana. Organizar sonidos, es decir componer, interpretar y escuchar no tiene bases naturales, sociales y culturales a partir de las cuales se construye el fenómeno musical. Castro ha comprendido esta relación compleja, pero no la ha tematizado, de modo que su intento pluridisciplinar ha quedado incompleto.

Analizar el flamenco "de lo remoto a lo tangible" (p. 13) significa alumbrar las lagunas del desarrollo musical en Andalucía y otras regiones de la Península. Esta perspectiva empirista es, según mi criterio, la más correcta y acertada para explicar el flamenco como fenómeno de la hibridación musical transcultural. Para el autor, que es músico y musicológico a la vez, esto significa "el estudio musical del flamenco para poder acercarnos a su historia" (ibíd.). Dicho de otro modo, no inventar ni el origen ni el carácter de la música flamenca desde la perspectiva de la imaginación, la anécdota 0 las preferencias étnicas, sino que reconstruir su historia (que es su desarrollo) a partir de su dinámica musical empíricamente contrastable en relación con el desarrollo social y cultural del campo artístico.

Castro ha organizado su obra en cuatro capítulos principales en los que analiza la evolución de los cantes hasta su primer apogeo y formación constitutiva que fecha con la muerte de Silverio Franconetti en 1889. Tras una breve introducción que abarca un "preámbulo" dedicado a su motivación para este trabajo y su intención de superar "los falsos mitos del origen gitano del cante flamenco y la época 'hermética', explica su intención de explicar "el papel del gitano como protagonista, tanto en la faceta interpretativa como en la creativa, aunque no exclusivo" (p. 14). Se empeña en demostrar que la denominación de un baile o cante como "gitano", tal como suele reflejarse en la documentación histórica, no se corresponde al carácter real del género sino más bien a tradiciones solamente consideradas como "gitanas", cuyas verdaderas bases se hunden en tradiciones andaluzas e incluso peninsulares. Podríamos decir, que en este aspecto el autor ha reconocido las conclusiones de muchos investigadores sociales y culturales surgidas a lo largo de los últimos 25 años.

Respecto a la metodología, el autor se ha servido de las transcripciones musicales de las primeras grabaciones de cantes a partir de 1895. Otras fuentes importantes eran las partituras de música de inspiración flamenca de autor con las que pudo explicar el papel del flamenco en el marco de la música de la época, las piezas instrumentales representadas por la influyente escuela bolera, recopilaciones de cantos populares procedentes de la labor de los folkloristas, los antecedentes guitarrísticos de las épocas del barroco y del renacimiento. Gracias a la extensa labor descriptiva del autor, se puede acceder a todos estos documentos en su página web.

En el primer capítulo discute una serie de conceptos básicos del análisis musicológico del flamenco, como por ejemplo las diferencias entre "lo flamenco" y "lo gitano", las influencias árabes y africanas, la tradición musical hispánica, la relación entre "lo popular", "lo folclórico" y "lo culto" en el flamenco, la diferenciación social y musical en la música, el papel de Silverio Franconetti para el flamenco como arte, las aportaciones de los folkloristas, las primeras fuentes musicales en los cancioneros de los siglos XIX y XX, así como algunas reflexiones sobre la terminología del flamenco.

El segundo capítulo está dedicado al análisis integral y muy comprensible del corpus musical del flamenco, es decir, a sus aspectos formales en torno a sus modalidades, melodías, armonías y ritmos/compases. Todo esto acompañado de ejemplos de partiduras y conclusiones didácticamente organizadas.

Basándose en su hipótesis del polifacético origen del flamenco, en el siguiente capítulo, Castro describe las formas musicales anteriores al género flamenco y la cronología de los estilos flamencos, seguido por el análisis de las formas musicales en modo Menor y Mayor, la práctica de hemiolia (la alternancia de compases de $6 / 8$ y compases de 3/4) así como las relaciones entre determinados bailes y danzas con el flamenco.

El capítulo cuatro se puede considerar como el núcleo temático de la tesis, pues abarca en catorce subcapítulos y más de 1500 páginas el análisis de los estilos flamencos, sus influencias de origen, sus variaciones, diferencias y afinidades así como sus 
relaciones con el baile y la danza. Es de particular interés que el autor ha resumido los contenidos y las conclusiones de estos subcapítulos, de modo que los lectores disponen de una síntesis útil y didácticamente valiosa para seguir sus argumentos. Otra rica fuente consiste en las muy numerosas transcripciones musicales de los estilos, sus variantes, diferencias y afinidades.

La presente monografía es el estudio musicológico más completo y serio hasta el momento, no sólo porque abarca todos los palos flamencos con sus descripciones detalladas, fuentes y partituras, sino porque los relaciona con el mundo musical, social y cultural a base de documentos de la época. Es el carácter empírico que destaca y que convierte el texto en una importantísima fuente de información tanto para musicólogos como estudiosos del flamenco.

Cabe destacar que la obra es básicamente musicológica en el sentido formal y queda incompleta al no profundizar en la dimensión social y cultural de la música reclamada ya por Guido Adler, el fundador de la disciplina, a finales del siglo XIX. Tampoco delimitado su análisis musicológico del flamenco de otras aportaciones anteriores, no las evalúa desde la perspectiva actual ni la posiciona claramente en el marco de la investigación que ha prosperado tanto a lo largo de las últimas décadas y que ha cambiado profundamente la comprensión del arte flamenco y su praxis.

Resumiendo: la obra es un paso gigante para el estudio musicológico del flamenco, la primera aportación integral en este campo, un resumen estratégico y la clave para la futura investigación de este género.

Gerhard Steingress Universidad de Sevilla, España

gst@us.es

Recibida: 01-12-2015

Aceptada: 15-01-2016

(c) (1) (3) 